\title{
EDUCAÇÃO E PARTICIPAÇÃO: TENDÊNCIAS E CAMINHOS PARA UMA GESTÃO DEMOCRÁTICA
}

Nadja da Cruz Silva ${ }^{1}$

\section{RESUMO:}

O trabalho versa sobre os estudos das ações democráticos e participativas no contexto social e político na contemporaneidade. Analisa os processos políticos e históricos da democratização da escola no Brasil. E aliada à democratização do ensino a importância de novos modelos e configurações de gestão democrática e participativa. Possibilitando traçar caminhos para autonomia das questões pedagógica, autogestão e a elaboração de políticas públicas voltadas para a democratização do acesso e permanência da educação escolar.

Palavras-chave: democracia, participação e pedagógico.

\section{ABSTRACT:}

The paper focuses on the studies of democratic and participatory actions in the social and political context in the contemporary. It analyzes the political and historical processes of the democratization of the school in Brazil. And together with the democratization of teaching, the importance of new models and configurations of democratic and participatory management. Making it possible to trace the autonomy of pedagogical questions, selfmanagement and the elaboration of public policies aimed at the democratization of access and permanence of school education.

Keywords: democracy, participation and pedagogy.

\section{INTRODUÇÃO:}

O presente estudo visa refletir sobre os processos democráticos e participativos delineados na educação brasileira. Partindo do princípio de que a participação é um importante elemento para o processo democrático da educação tanto no âmbito escolar formal, não formal como para o fortalecimento e elaboração das políticas públicas voltadas para a educação.

\footnotetext{
${ }^{1}$ Professora da Educação Básica. Graduada em Pedagogia pela Universidade Federal da Bahia. Especialista em Gestão e Desenvolvimento de Pessoas. Mestranda em Educação pela Universidade do Estado da Bahia/ Programa de Educação e Contemporaneidade - PPGeduc. Linha de Pesquisa III: Educação, Gestão e Desenvolvimento Local Sustentável. Vinculada ao grupo de Pesquisa: Teoria Social e Projeto Político Pedagógico sob a orientação do professor Dr. Eduardo José Fernandes Nunes.

E-mail: nadjacruzsilva@yahoo.com.br
} 
Analisa os traços históricos dos processos democráticos no contexto político do nosso país. Partindo das lutas reivindicatórias, dos espaços de educação não formal até chegar ao ambiente escolar, no espaço de diálogo, luta e reflexão igualmente importante quanto os outros espaços. Tratar do princípio participativo na educação é considerar que o exercício da democracia inicia-se, aprende-se e vivencia-se nos processos educativos, no cotidiano e vivência da escola.

Compreender que as lutas reivindicatórias contribuíram para a construção da nova LDB (Lei de Diretrizes e Bases da Educação Nacional) 9394 de 1996, sobretudo no seu artigo 14 que revela uma nova forma de enxergar os processos democráticos dentro do espaço escolar. A abertura para uma gestão democrática, eleições para gestores escolares, formação e estruturação dos conselhos escolares indicam iniciativas importantes para democratização da educação no país e para a valorização da participação nas estruturas macro e micro da educação nacional.

\footnotetext{
Art. $14^{\circ}$. Os sistemas de ensino definirão as normas da gestão democrática do ensino público na educação básica, de acordo com as suas peculiaridades e conforme os seguintes princípios:

I - participação dos profissionais da educação na elaboração do projeto pedagógico da escola;

II - participação das comunidades escolar e local em conselhos escolares ou equivalentes.
}

A participação e o envolvimento de toda a equipe escolar e da comunidade constituem-se enquanto elemento fundamental para minimizar o exercício do poder de forma autoritária e repressiva. Participar, portanto assume uma conotação de questionamento e inquietação frente às ações do poder no ambiente escolar.

Pensar em alternativas de fortalecimento da gestão democrática através da autonomia dos sujeitos, da participação e de práticas de autogestão é um dos caminhos para estruturação da gestão democrática no espaço escolar e para o distanciamento das relações de poder autoritárias. Como afirma Girox (2003) a democracia é um principio definidor da educação e da vida cotidiana. E para que está ideia consolide-se nas diversas estruturas sociais é preciso o diálogo, através da valorização do ensino público e construir uma cidadania ativa e crítica.

\section{ESCOLA E DEMOCRACIA:}

A estruturação em sistemas de ensino da educação brasileira surge em meados do século xix com o intuito de atender a nova classe econômica que acabara de surgir. A 
estrutura de ensino passava-se por reformulações para atender esta nova classe econômica e social que constituía-se e visava a formação de pessoas que fossem ocupar postos de trabalho socialmente legitimados pela sociedade como sendo de comando e chefia. E para isto, a escola precisava ser pensada e construída em uma perspectiva diferente. Uma perspectiva para preencher postos de trabalhos diferenciados, entre quem realiza atividades intelectuais e manuais.

\footnotetext{
Nesse sentido, advogar escola para todos correspondia ao interesse da burguesia, porque era importante uma ordem democrática consolidada e correspondia também ao interesse do operário, proletário, porque para ele era importante participar do processo político, participar das decisões. (SAVIANI, 2009, p.48)
}

A influência das teorias crítico- produtivistas permitiram a criação de um sistema educacional nacional para atender os interesses da nova classe (burguesia) que se formava. A escola é um dos espaços por onde a ideologia dominante do sistema capitalista consolidaria o seu discurso. E onde acontecia a distinção entre o formar e o profissionalizar, a educação direcionada para a elite e a educação voltada para as classes operarias.

O pensamento democrático da educação validou uma escola mais acessível as classes populares e ensaiou uma maior atuação no que diz respeito a participação dos sujeitos no processo político e democrático. Esses ideais inspiraram os princípios de uma escola democrática e aberta.

A construção de espaços democráticos dentro da escolar constitui-se um grande desafio, pois requer intervir nas estruturas de poder já enraizadas no contexto da escola. A formação de escolas essencialmente democrática e participativa de acordo APPLE (1997) significa que essas escolas serão geridas por Comitês, conselhos e outros grupos que tomam decisões no âmbito da escola incluem não apenas educadores profissionais, mas também os jovens, seus pais e outros membros da comunidade escolar, através de um planejamento cooperativo.

\section{PROCESSOS PARTICIPATIVOS NO BRASIL:}

O processo de participação ao longo da história do Brasil se deu de forma tolhida e fragmentada. Isto, devido a uma herança clientelista, pautada em privilégios de classe, econômicos e políticos. Assim, os processos de participação e decisões estavam concentrados nas mãos de uma minoria dominante e as tentativas de participação popular em vários momentos foram sucumbidas e/ou abafadas por uma atitude de tutela por parte do Estado. 
Em parte é possível se afirmar que a elaboração da constituição de 1988 configurouse como uma transição entre a saída de um período ditatorial e o inicio de uma participação mais aberta às camadas populares. Mas esse processo de abertura democrática do país, foi complexo, não foi algo tranquilo e harmônico foram necessárias diversas formas de manifestações populares tais como: passeatas, protestos e assembleias, até se colocar tais ações no âmbito legal para os direitos e deveres do cidadão, principalmente a conquista do direito de participar e opinar, ou pelo menos, expressar as insatisfações da população. É preciso também compreender que a consciência de que participar é importante para o processo democrático do país é algo que deve ser construído e discutido nos diversos espaços sociais, sejam eles formais ou não formais.

No âmbito social brasileiro é marcante a presença de um contexto histórico-social caracterizado pelo exercício do poder de forma autoritária, clientelista e pouco participativa é cada vez mais difícil fomentar práticas democráticas e posicionar-se de forma participativa no exercício do poder. É imprescindível que possamos inserir noções de descentralização e participação cidadã nos diversos espaços de sociabilidade. Isto, porque a sociedade organizada ou não clama por uma democracia não apenas representativa, em que as decisões são tomadas por poucos sobre o destino do coletivo, mas que o processo democrático possa ser autônomo e de fato participativo.

A dificuldade em construir uma participação efetiva consiste em experiências históricas pautadas em valores autoritários aliados a falta de uma conscientização política. Temos arraigado na nossa historia do ponto de vista econômico. Social, politico e cultura brasileira uma herança clientelista baseada no autoritarismo e na delegação de poder; o que facilita a alienação e a acomodação.

É importante destacar que os diferentes interesses sociais nem sempre são convergentes com os interesses da coletividade, esse conflito de interesses pode resultar no enfraquecimento do processo de participação social. Para Bordenave (1994, p.41) "a participação não pode ser igualitária e democrática quando a estrutura de poder concentra as decisões numa elite minoritária”. Assim, é evidente que quando as estruturas de poder das classes dirigentes e seus privilégios estão ameaçados as questões que dizem respeito à coletividade são colocadas em segundo plano ou descartadas.

Para Peruzzo (1998, p.78-79) a participação coloca-se em três modalidades de ação coletiva que são: participação passiva, participação controlada e participação-poder. O primeiro tipo de participação ocorre quando o individuo delega a outra pessoa o poder de decisão ou escolha, o que de acordo com a autora favorece que as decisões sejam 
verticalizadas de cima para baixo. Em seguida a participação controlada é concedida de cima para baixo e controlada com base em algumas restrições, é caracterizada pela limitação ao realizar determinada ação, ou seja, só é possível quando as instâncias detentoras do poder permitem. Já na participação controlada manipulável a legitimação do poder ocorre de forma velada a fim de adequar aos interesses de quem detém o poder. No terceiro tipo, participação- poder é constituído de elementos que favorecem a participação democrática, ativa e autônoma em que o exercício do poder é compartilhado e tem como expressões a cogestão e a autogestão.

No interior das práticas participativas estão implícitas e explicita diversas manifestações de poder, que vária de uma participação tutelada e fragmentada a efetivas práticas de participação. Para Ammann (2009, p.12) a classe dominante exerce seu poder no seio das classes subordinadas, sob duas formas, através do consenso e hegemonia no nível da sociedade civil e sob a forma de ditadura na sociedade política, decorrente da manifestação dos diversos tipos de poder que ocorre no meio social. Contudo, o exercício do poder e da dominação do sujeito, nem sempre ocorre através da coerção, mas sim através do consenso e da legitimação das ações do outro.

Paro (2008) conceitua poder destacando que o mesmo possui diferenciados usos. Dentre esses o autor vai ater-se aquele que supõe o ser humano como sujeito. E a esse respeito o poder pode ser visto sob duas perspectivas: "o poder como capacidade de agir sobre as coisas e o poder como capacidade de determinar o comportamento do outro" (Paro, 2008, p.32). O exercício do poder depende da aceitação do indivíduo ou grupo para se concretizar.

No que tange a participação popular inserida no contexto dos movimentos sociais Gohn (2004) afirma que com o fim do regime militar, a partir de 1985, passa existir uma maior abertura dos canais de participação, abertura política e um redirecionamento do significado de sociedade civil, assim como o destaque dos movimentos sociais populares urbanos e os novos atores sociais na luta pelos direitos sociais e culturais modernos. No que diz respeito ao processo de participação no Brasil é importante destacar que a década de 90 foi marcada por vários debates e mobilizações em torno da conquista da cidadania o que deu espaço a um novo desenho dos movimentos sociais. Já os movimentos populares de bairro retraem-se, ganham destaque as organizações comprometidas com questões mais amplas. E as questões básicas defendidas pelos movimentos de bairro ficam em áreas delimitadas e restritas a vida cotidiana. 
A instituição escolar no contexto atual precisa adotar uma cultura participativa e uma atuação cidadã frente aos desafios da sociedade contemporânea a fim de contribuir para a redução das desigualdades e democratizar as relações de poder nos diversos espaços. E inserir nos currículos escolares uma aprendizagem pautada na participação dos sujeitos, buscando potencializar a atuação da comunidade escolar e local.

\section{EDUCAÇÃO E PARTICIPAÇÃO:}

A participação é um dos vieses para traçar o percurso de uma gestão democrática seja no contexto educacional ou escolar. A ideia de participação vem aliada ao processo de democratização da educação pública no Brasil. No inicio da década de 80 começou o movimento de mudança na forma de gerir as escolas públicas no país. Isto associada a ideia de eficiência e qualidade da educação pública. O movimento de reorganização da gestão escolar no Brasil congrega três vertentes que são: participação da comunidade escolar na seleção dos gestores da escola; criação de um colegiado/conselho escolar que tenha autoridades deliberativas, repasse de recursos financeiros às escolas e consequentemente maior autonomia. (LÜCK. et al. 2012)

O processo de participação constitui-se um princípio importante no espaço escolar, sobretudo no delineamento da gestão democrática. $\mathrm{O}$ conceito de participação precisa ter o seu sentido ressignificado a partir do momento em que os sujeitos atribuem sentido ao ato de participar, nos diversos espaços que ocupam. O que revela uma gradativa aproximação entre o que está redigido nos dispositivos legais sobre participação e a sua prática ativa e efetiva.

Compreender a escola como espaço de construção participativa e colaborativa é a abarcar a ideia do princípio de uma gestão participativa pautada no compartilhamento do poder e autonomia dos sujeitos. O que é traduzido em maior qualidade pedagógica, comprometimento da comunidade escolar e local.

Para Demo (1996) a participação é considerada uma conquista e configura-se como uma constante busca, é processo, portanto não pode ser entendida como concessão, nem ter seu espaço delimitado, mas é resultado de uma tomada de consciência e de suas condições enquanto sujeito do tecido social. A participação por sua vez revela outras formas de poder que podem ser partilhados, ou seja, com características democráticas, participativa e de autonomia ou pode revelar-se com características autoritárias e controladoras. O autor chama a atenção para as supostas aberturas dos canais de participação oferecidos pelo 
governo, e afirma que na realidade é mais um elemento para camuflar as ideologias dominantes e suas formas de exercício do poder, assim:

[...] quem acredita em participação, estabelece uma disputa com o poder. Trata-se de reduzir a repressão e não de montar a quimera de um mundo naturalmente participativo. Assim, para realizar participação, é preciso encarar o poder de frente, partir dele, e, então, abrir os espaços de participação, numa construção arduamente levantada, centímetro por centímetro, para que não se recue nenhum centímetro. Participação, por conseguinte, não é ausência, superação, eliminação do poder, mas outra forma do poder (grifo do autor). (DEMO, 1996, p.20).

Paro (2008) destaca a possibilidade da constituição de sujeitos livres e uma educação com vista a evidenciar práticas democráticas. A orientação pedagógica tradicional que costuma nortear as escolas brasileiras resiste ou desconhece a ideia dos alunos serem detentores do poder. Ignora-se o processo de interação dos sujeitos e visualizam o processo pedagógico como uma mão única que vai do professor que ensina para o aluno que aprende passivamente. Por outro lado, o professor manifesta o seu poder no sentido de mudar comportamentos e no exercício de sua função.

A escola que não prevalece à formação de sujeitos autônomos e independentes contribui para o fortalecimento de uma cultura da acomodação e passividade, em que aluno 'obediente' é o que aceita as determinações do professor sem questionar e encara a dominação dos indivíduos como algo natural. O trabalho individualizado cuja finalidade é preparar os indivíduos para o mercado de trabalho reforça o egocentrismo e favorece um clima de disputa. O que contribui para acirrar as relações de poder na comunidade escolar.

Para Jacobi, 2000, a participação deve ser compreendida como um fator essencial para o processo de democratização do poder público e constitui-se como um espaço vital para o fortalecimento de uma cidadania ativa e para o processo de democratização. As práticas participativas trazem a tona uma maior conscientização da cidadania ativa e sua interação na sociedade civil.

Levar a cultura da participação para o ambiente escolar não é uma atividade t'ranquila e de fácil implementação. Incentivarem os sujeitos a participarem significa uma disputa direta com o poder, ainda que os documentos de legitimação legal da educação brasileira como na Lei de Diretrizes e Bases da Educação Nacional (LDB) reafirmem a importância da construção de espaços participativos e de autonomia pedagógica e financeira nas modalidades de ensino ainda presenciamos experiências de ações truculentas de autoritarismo. Uma vez que o compartilhamento do poder ainda é muito limito e restrito, sair 
deste lugar de comodismo e passar a ter uma participação atuante nos lacais que ocupam é algo que é construído e trabalhado paulatinamente.

\section{AUTOGESTÃO:}

De acordo com as descrições de modalidades de participação apresentadas por Peruzzo (1998) a autogestão enquadra-se como uma das expressões do poder-participação que é uma modalidade de participação constituída com base em processos que favorecem ações democráticas, ativas e autônomas, propiciando o crescimento dos sujeitos. A autogestão está relacionada a participação direta da população nas estruturas do poder e nos espaços de atuação, refere-se a tomada de decisões e a interferência direta de situações de ordem social, politica, econômica e cultural. Quando as decisões para a resoluções de questões são delegadas as pessoas escolhidas são "responsáveis perante seu eleitorado, demissíveis, sujeitos à retroatividade e sem privilégios (p.84)". Na perspectiva da autogestão não se resume em deixar as deliberações para outras pessoas resolverem, é delegar a pessoas que tenham compromisso com a coletividade.

Enfim, autogestão não deve ser confundida com formas que não possibilitem o autogoverno ou a participação efetiva de todos, diretamente ou por meio de delegados representativos nos diversos níveis de decisões. Ao que tudo indica, ela, em sua plenitude, relaciona-se com a mais profunda utopia de igualdade, liberdade e desalienação, como uma fonte alternativa na busca de uma nova sociedade e de um novo homem. (PERUZZO, 1998, p. 86)

Pensar nos mais altos níveis de participação é pensar na autogestão em que as decisões são compartilhadas mediante os mecanismo de codecisão e colegialidade. E entre as formas colegiadas de se tomar decisão estão os comitês e os conselhos. É a experiência da efetiva autonomia, onde os sujeitos organizam e decidem suas vidas de acordo com as demandas e necessidades do grupo e a distância entre administrador e administrados vão atenuando.

Bordenave (1994) identifica a autogestão como um dos mais altos níveis da participação no contexto social, em que o controle das atividades e ações do grupo é mantido pelo próprio grupo de forma genuinamente coletiva. E os membros do grupo passam de uma posição de receptores de informações ou apenas consultados para serem gestores autônomos das decisões do grupo, responsáveis pelo desenvolvimento de suas ações. Ainda de acordo 
com o autor a democracia participativa promove a subida da população a níveis elevados de participação e tomada de decisões.

A tentativa de trazer experiências autogestionárias para a educação configura-se como uma grande oportunidade de repensarmos os modelos de gestão educacional presentes na educação brasileira na contemporaneidade. É pensar uma gestão com mais autonomia, envolvendo os sujeitos que fazem parte do processo pedagógico escolar. A prática e o exercício constantes de elementos democráticos e de maior autonomia das questões educacionais configuram-se passos iniciais de uma autogestão pedagógica, em que a condução das questões pedagógicas gira em torno dos sujeitos que fazem e vivem o ambiente escolar e da educação. Centrar a ação pedagógica nos sujeitos e não em resultados voltados para o preenchimento de números das instituições burocráticas da educação.

As práticas educativas autogestionárias podem ser perpetradas em vários espaços do ambiente escolar, desde que estejam inseridas em um grupo que tenha um entendimento e uma concepção ampliada de autogestão. Também ser praticada no exercício da sala de aula, nas lutas reivindicatórias por melhores condições de trabalho. Está atento para as transformações que cada sujeito pode realizar com a sua ação no seu ambiente de atuação profissional.

\section{CONSIDERAÇÕES FINAIS}

Em meio ao contexto atual marcado por tantas incertezas, angústias e efemeridades, marcas presentes no contexto da pós-modernidade. Persistimos com a ideia de que a escola é construída e reconstruída do ponto de vista ideológico e político pelos sujeitos que nela vivencia o seu cotidiano. $\mathrm{E}$ os sujeitos que vivenciam este espaço possam contribuir na transformação do ambiente escolar e pensar que cada atitude, ação ou iniciativa pode convergir para uma práxis pedagógica democrática e transformadora.

Possibilitar a autonomia das pessoas, valorizando a sua prática, a importância do diálogo e de uma compreensão ampla das dimensões pedagógicas, políticas e culturais presentes na dinâmica pedagógica dos espaços de educação.

De acordo com Apple (1997) a democracia é o princípio fundamental da relação política e social. E à medida que usamos para avaliar o progresso político de outros países. A palavra democracia foi usada em muitos momentos e continua sendo usada como manobra politica e militar. O conceito de democracia na sociedade atual tem sido um tanto ambíguo, 
pois ao mesmo tempo que defende direitos civis, eleitorais também e usada para favorecer a economia de livre mercado. Que claramente tende a beneficiar a classe hegemônica.

Exercer a democracia muitas vezes envolve tensões e contradições. A participação democrática na tomada de decisões, por exemplo, abre possibilidades para ideias antidemocráticas. Mas a vida democrática equivale sempre a lutar e que possamos pensar e construir escolas com ideais democráticos, idealizadas e geridas pela comunidade escolar, autônoma e cooperativa.

É preciso ampliar os olhares frente ao desafio de gerir as escolas pautadas em práticas democráticas augestionárias. Com uma preocupação mais voltada para a comunidade escolar e para uma práxis pedagógica transformadora. Descentralizando-se dos sistemas macro de educação, que de forma geral preocupam-se mais números frios do que com a dimensão humana dos sujeitos.

Expressões de um trabalho democrático e participativo no contexto do espaço escolar é a construção e reconstrução do projeto político pedagógico, documento que direciona e revela a identidade da escola, seu direcionamento político e ideológico.

As formações desses espaços democráticos dependem de um trabalho de formação e política e conscientização dos sujeitos que fazem parte do ambiente escolar. As relações democráticas dentro destes espaços perpassam por relações de poder que nem sempre convergem para os interesses do coletivo. $\mathrm{O}$ que pode ocasionar o enfraquecimento do processo participativo dos sujeitos. Para Bodernave (1994) a participação não pode ser igualitária e democrática quando a estrutura de poder concentra as decisões numa elite minoritária.

\section{REFERÊNCIAS:}

APPLE, Michael W; BEANE, James (orgs) Escolas democráticas. São Paulo: Cortez, 1997.

AMMANN, Safira Bezerra. Ideologia do desenvolvimento de comunidade no Brasil. 11. ed. São Paulo: Cortez, 2009.

BRASIL. Lei de Diretrizes e Bases da Educação Nacional de 1996. Disponível em: http://portal.mec.gov.br/arquivos/pdf/ldb.pdf acessado em 15 de Dezembro de 2017.

BORDENAVE, Juan E.Díaz. O que é participação. 8. ed. São Paulo: Brasiliense, 1994.

DEMO, Pedro. Participação é conquista: noções de política social participativa. 3. ed. São Paulo: Cortez, 1996.

Revista Educação e Ciências Sociais, Salvador, v.1, n.1, 2018. 
GIROUX, Henry A. Atos impuros: a prática dos estudos culturais. Porto Alegre: Artemed, 2003.

GOHN. Maria da Glória. Empoderamento e participação da comunidade em políticas sociais. Saúde soc. vol.13 no. 2 São Paulo Maio/Agosto. 2004.

JACOBI, P. R. Educação, ampliação da cidadania e participação. Educação e Pesquisa. Vol.26 no.2 São Paulo Julho/Dezembro.2000

PARO, Vitor Henrique, Educação como exercício de poder: critica ao senso comum em educação. São Paulo: Cortez, 2010.

PERUZZO, Cecília Maria Krohling. Comunicação nos movimentos sociais populares: a participação na construção da cidadania. Rio de Janeiro: Vozes,1998.

SAVIANI, Dermeval. Escola e democracia. 41. ed. São Paulo: Autores associados, 2009. 